\title{
ensaio
}

\section{ARTIGO \\ ESTUDOS DE PERCEPÇÃO E EDUCAÇÃO AMBIENTAL: UM ENFOQUE FENOMENOLÓGICO}

\author{
Alanza Mara Zanini' \\ https://orcid.org/0000-0003-0687-1512 \\ José Anderson de Oliveira ${ }^{4}$ \\ https://orcid.org/0000-0002-7156-3957
}

\author{
- Amanda Ribeiro dos Santos ${ }^{2}$ \\ https://orcid.org/0000-0003-1038-731X \\ Marcelo Borges Rocha 5 \\ https://orcid.org/0000-0003-4472-7423
}

\author{
Chreiva Magalhães Malick ${ }^{3}$ \\ http://orcid.org/0000-0001-6554-3135
}

\section{RESUMO:}

Os estudos de percepção ambiental destacam-se como importante estratégia para conhecer a relação entre ser humano e natureza, a fim de oportunizar o estudo reflexivo das questóes ambientais. A perspectiva fenomenológica relaciona-se aos estudos de percepção ambiental, tendo em vista que considera as formas individuais de sentir e perceber o espaço vivido. Este estudo buscou refletir sobre a importância dos estudos de percepção ambiental e seus aspectos dialéticos, axiológicos e fenomenológicos, no que diz respeito à educação formal e não formal. Para isso, foi feita uma análise documental sobre os assuntos pertinentes às temáticas percepção e educação ambiental, a partir do diálogo entre marcos teóricos da literatura. Consideramos que seja possível, com as contribuições da percepção ambiental para a educação formal e não formal, reinventar uma ordem social que seja mais justa, democrática e ambientalmente segura.

\section{ESTUDIOS DE PERCEPCIÓN Y EDUCACIÓN AMBIENTAL: UN ENFOQUE FENOMENOLÓGICO \\ RESUMEN:}

Los estudios de percepción ambiental se destacan como una importante estrategia para conocer la relación entre el ser humano y la naturaleza, a fin de posibilitar el estudio reflexivo de las cuestiones ambientales. La perspectiva fenomenológica se relaciona con los estudios de la percepción ambiental, ya que considera las formas individuales de sentir y percibir el espacio vivido. Este estudio buscó reflexionar sobre la importancia de los estudios de percepción ambiental y sus aspectos dialécticos, axiológicos y fenomenológicos, con respecto a la educación formal y no formal. Para ello, se realizó un análisis documental sobre los temas relevantes para la percepción y la educación ambiental, a partir del diálogo entre marcos teóricos de la literatura. Consideramos que es posible, con los aportes de la percepción ambiental a la educación formal y no formal, reinventar un orden social más justo, democrático y ambientalmente seguro.
Palavra-chave:

Percepção;

Fenomenologia;

Educação ambiental.

Palabras clave:

Percepción;

Fenomenología;

Educación ambiental.

\footnotetext{
1 Universidade Federal do Rio de Janeiro, Rio de Janeiro, RJ, Brasil.

2 Rede privada de ensino, Duque de Caxias e do Rio de Janeiro, RJ, Brasil.

3 Prefeitura da cidade do Rio de Janeiro, RJ, Brasil.

4 Rede privada de ensino, Petrópolis, RJ, Brasil.

5 Centro Federal de Educação Tecnológica Celso Suckow da Fonseca, Rio de Janeiro, RJ, Brasil.
} 


\title{
SOCIAL TECHNOLOGY IN THE PROGRAMMING OF A CRITICAL-TRANS- FORMATIVE CURRICULUM IN SCIENCE EDUCATION
}

\author{
ABSTRACT: \\ Studies of environmental perception stand out as an important strategy to know the re- \\ lationship between human beings and nature, in order to provide a reflective study of the \\ issues environmental. The phenomenological perspective is related to environmental per- \\ ception studies, as it considers the individual ways of feeling and perceiving the lived space. \\ This study attempts to reflect about the importance of environmental perception studies \\ and their dialectical, axiological and phenomenological aspects, with regard to formal and \\ non-formal education. For this, a documental analysis was made on the issues relevant to \\ the thematic perception and environmental education, based on the dialogue between the- \\ oretical frameworks of the literature. We believe that it is possible, with the contributions \\ of environmental perception to the formal and non-formal education, to reinvent a social \\ order that is more just, democratic and environmentally safe.
}

\author{
Keywords: \\ Perception; \\ Phenomenology; \\ Environmental \\ education.
}

\section{INTRODUÇÃO}

O mundo vive, há mais de um ano, a pandemia de Covid-19, uma infecção viral de origem zoonótica. $\mathrm{O}$ agente infeccioso dessa doença, Sars-CoV-2, é oriundo de animais silvestres, mas adquiriu a capacidade de saltar entre diferentes espécies - incluindo a habilidade de infectar o ser humano (Acosta et al., 2020). Entre os diversos debates que têm sido levantados sobre a problemática da pandemia, também tem sido discutido sobre a forma como os seres humanos se relacionam com o ambiente.

De forma deliberada ou não, estamos envolvidos na geração de impactos ambientais, pois precisamos continuar a produzir alimentos, matéria prima e energia. Na verdade, temos que aumentar a produção, pois a população humana continua em crescimento. Nesse contexto, ressalta-se a importância do desenvolvimento de estudos de percepção ambiental, como forma de conhecer as atuais relações que os diversos atores sociais estabelecem com o ambiente e pensar em estratégias para tornar mais sustentáveis os setores produtivos, reduzir os impactos ambientais e promover a melhoria da qualidade de vida humana.

A crise ambiental estabelecida evidencia a necessidade de mudanças drásticas de comportamento e atitudes humanas, a fim de que a insustentabilidade econômica, ambiental e social não defina o futuro global. Conforme destaca Kuhnen (2009, p. 38), uma transformação cultural deve ocorrer e deve ser organizada "em torno de quatro relacionamentos-chave: com a natureza, com o tempo, uns com os outros, e com a autoridade e o Estado".

Para a compreensão das problemáticas ambientais, é necessário o exercício da compreensão particular de cada sujeito, pois cada um possui uma interpretação individual do espaço que nos cerca, refletidas de seu contexto histórico-cultural. Leff (2001) ressalta que os saberes e as percepçôes são condicionados pelos contextos geográfico, ecológico e cultural em que se constroem e se desenvolvem as formações sociais.

A percepção consiste na aquisição, interpretação, seleção e organização das informações obtidas pelos sentidos (Helbel \& Vestena, 2017). Assim, por meio da percepção, um indivíduo é capaz de interpretar e organizar o significado que o ambiente lhe estabelece. Por isso, os estudos de percepção ambiental destacam-se como importante estratégia para conhecer a relação entre ser humano e natureza, a fim de oportunizar ao sujeito o estudo reflexivo das questôes ambientais. 
As percepções de cada indivíduo são dadas a partir de reflexos do espaço (lugar) vivenciado por ele, ou seja, de sua realidade captada por seus órgãos dos sentidos atrelada à sua complexa cognição. Se todos os sujeitos percebessem os objetos (materiais e imateriais) da mesma forma, não haveria divergências de percepçôes. Logo, a subjetividade é o elemento responsável por distintas percepçôes entre os sujeitos sobre um mesmo objeto. Cabe destacar que "não existe percepção errada ou inadequada, existem sim, percepçôes diferentes, condizentes com o espaço vivido" (Oliveira, 2006, p. 35).

A Psicologia é a ciência que estuda as concepçôes objetivas e subjetivas do sujeito. Os mecanismos e as leis de mudanças no comportamento e nas estruturas do pensamento são investigados pela Psicologia do Desenvolvimento (Xavier \& Nunes, 2015). A partir disso, em uma perspectiva psicológica, a percepção humana pode ser compreendida como sua interação com a realidade circundante, por meio dos órgãos dos sentidos. A percepção é construída a partir de sua relação psíquica com o meio, no contexto das açóes realizadas.

Para satisfazer uma necessidade, por exemplo, o indivíduo age conscientemente direcionando a sua atividade a um objeto específico. A relação entre sujeito e objeto, mediada por um instrumento, tem total dependência cognitiva do reflexo psíquico do indivíduo. Ou seja, depende de como a sua consciência interpreta seu objeto e as condiçốes de realização da atividade (Leontiev, 1978).

Diante dessa perspectiva teórica, pode-se dizer que a percepção que cada indivíduo estabelece com seu objeto e com seu instrumento, ocorre a partir de representações construídas tanto subjetiva quanto objetivamente. Nesta, as representações seriam formadas a partir de um processo de 'cristalização' das características e qualidades que foram sendo sedimentadas na sociedade ao longo do tempo.

Os problemas atuais, relacionados, principalmente, à crise ambiental que a sociedade tem enfrentado, parecem decorrer da falta de conciliação entre desenvolvimento e sustentabilidade. Assim, é urgente descobrir novos modos de viver, compreendendo como o sujeito percebe o ambiente e com ele se relaciona, tendo em vista que suas açốes estão atreladas à sua percepção de lugar. Segundo Marin (2008):

É somente na redescoberta desses modos de viver e de se relacionar com a natureza, o lugar habitado e a coletividade, que se pode ancorar uma postura sensível e proativa e uma discursividade enraizada, crítica, capaz de gerar o comprometimento das pessoas, focos das metas da educação ambiental (p. 216-217).

Para Kuhnen (2009) "uma das saídas, quem sabe, estaria em ampliar a noção de sustentabilidade para além do desenvolvimento econômico” (p. 38). Nesse sentido, torna-se imprescindível a tomada de açóes, por medidas coletivas, a fim de que os problemas ambientais possam ser amenizados. A responsabilidade não se restringe a um âmbito da sociedade, mas cabe à esfera governamental e às iniciativas sociais e educacionais o planejamento e a execução conjunta de açôes para a sensibilização da sociedade quanto à conservação ambiental, a partir de uma percepção integrada entre o indivíduo e o ambiente.

$\mathrm{Na}$ educação ambiental (EA) é fundamental a utilização de referenciais teórico-metodológicos que subsidiem um ensino transformador das percepçôes dos indivíduos, capaz de possibilitar o empreendimento de açốes comprometidas em prol da conservação ambiental e melhoria da qualidade de vida humana. Estudos de EA revelam ser capazes de contribuir para a construção de novas percepções e valores dos sujeitos quanto à natureza, podendo resultar em açôes que evitem a dicotomia entre ser humano e ambiente, no contexto de desenvolvimento e sustentabilidade.

Dessa forma, a partir de marcos teóricos relevantes na área, este estudo teve como objetivo refletir sobre a importância dos estudos de percepção ambiental e seus aspectos dialéticos, axiológicos e fenomenológicos, no que diz respeito à educação formal e não formal. 


\section{CONCEITO DE PERCEPÇÃO AMBIENTAL}

A diversidade de significados, nos diferentes dicionários, associada ao vocábulo "percepção" (termo originário do latim, perception), revela ser um desafio aos processos de EA. A polissemia do termo reverbera em diferentes categorias na Filosofia - como ideia, sensação, imagem, intuição, estímulo, dentre outras -, influenciando a condução das pesquisas relacionadas ao termo percepção ambiental (Marin, 2008).

Tanto a percepção quanto a sensação sofreram influências em dois campos da Filosofia, como o empirismo e o racionalismo. No século XX, as duas tradiçóes são alteradas na Filosofia pela "teoria da Gestalt" ou “psicologia da forma” e pela fenomenologia (Oliveira \& Mourão-Júnior, 2013).

Até a década de 1960, estudos sobre o ser humano e sua relação com o ambiente caracterizam-se como dispersos por não se concentrarem em um campo específico. De acordo com Marin (2008), a tentativa da compreensão da percepção como fenômeno antecede ao surgimento da Psicologia, relacionando-se aos estudos que buscavam o entendimento dos mecanismos físicos e biológicos que definiam os fenômenos. Desde então, ramos da Psicologia passaram a investigar os processos ligados à percepção, sendo que a Psicologia Ambiental baseou-se, inicialmente, nas abordagens do behaviorismo, estruturalismo e introspeccionismo (mentalismo) (Marin, 2008). Com a Psicologia Ambiental e outras áreas de conhecimento, houve a superação do tipo de enfoque de suas abordagens sobre a percepção, a partir dos princípios da psicologia da forma ou Gestalt, estreitando seus entendimentos nos fundamentos da fenomenologia e no existencialismo.

Especificamente, a Psicologia Ambiental superou abordagens tradicionais que desenvolveram seus estudos de percepção a partir de situações controladas em laboratório. Estes estudos levavam em consideração uma percepção que não compreendia toda a complexidade existente na relação humana com sua realidade imediata.

A característica do uso dos sentidos no reconhecimento do mundo e resposta a estímulos, revela a base conceitual originalmente utilizada nos campos da Psicologia, mais enfaticamente, na Psicologia Comportamentalista (Marin, 2008). No entanto, por encontrarem-se teorias sobre percepção em diversas áreas, esta assume diferenciados enfoques.

Do ponto de vista das teorias do conhecimento, existem diferentes correntes que procuram explicar as sensações e a consequente origem das percepções do ser humano em relação ao meio em que vive: corrente empirista, corrente intelectualista e corrente fenomenológica (Chauí, 1998). Krzysczak (2016) evidencia que os estudos de percepção foram fundamentados pela tradição filosófica nas concepções empirista e intelectualista. De modo geral, estas duas concepçôes consideram a separação entre sujeito-objeto.

A corrente empirista considera que todo o conhecimento do mundo exterior depende da experiência adquirida por meio dos sentidos, ou seja, o conhecimento é resultado dos estímulos sensoriais (Chauí, 2000). Francis Bacon, Thomas Hobbes, George Berkeley e John Stuart Mill, John Locke, David Hume são filósofos associados à corrente empirista. Nessa perspectiva, os estímulos exteriores atuam sobre os sentidos e estes no sistema nervoso humano, promovendo as sensações e, consequentemente, originando diferentes percepções. As experiências sensoriais deixam impressões em nossas mentes, o que permite a aquisição de conhecimento. Cabe ressaltar que, nessa corrente, a experiência é externa e interna: a primeira realiza-se pela sensação e proporciona a representação dos objetos externos: cores, sons, odores, sabores, extensão, forma, movimento; enquanto a segunda realiza-se pela reflexão, que proporciona a representação das próprias operações exercidas pelo espírito sobre os objetos da sensação, como: conhecer, crer, lembrar, duvidar, querer (Portugal, 2002). $\mathrm{Na}$ tradição empirista a sensação conduz à percepção como síntese ativa; no entanto, quando o pensamento formula as ideias puras, a percepção deve ser abandonada por ser considerada não muito confiável para o conhecimento, uma vez que está propensa às ilusões (Chauí, 2000).

A corrente intelectualista defende que nem todo o conhecimento do mundo externo se baseia na experiência. Aristóteles foi o fundador dessa corrente, tendo como discípulo São Tomás de Aquino (responsável pela 
reorganização da corrente na Idade Média) (Faitanin, 2008). Nessa perspectiva, segundo Faitanin (2008), o ser humano deve, em sua capacidade sensitiva, não apenas receber os estímulos sensoriais, mas percebê-los, imaginá-los, associá-los e conservá-los. Desse modo, a sensação e a percepção dependem do sujeito do conhecimento, de modo que o exterior é apenas um estímulo a mais para a sensação: o sujeito é ativo e os fatores externos são passivos.

Já, para a abordagem fenomenológica, não há dicotomia entre sujeito e objeto:

o objeto deixa de ser meramente externo, tornando-se então um agrupamento de aspectos perceptivos e funcionais, onde se considera importante a relação entre objeto e aquele que o percebe (Krzysczak, 2016, p. 3).

O tópico seguinte abordará, de forma mais específica, o enfoque fenomenológico associado aos estudos de percepção ambiental.

\section{A PERCEPÇÃO AMBIENTAL NUMA PERSPECTIVA FENOMENOLÓGICA}

A corrente fenomenológica surgiu no século XIX, tendo o matemático alemão Edmund Husserl (1859 - 1938) como seu criador (Martin Sala, 2018), embora tenha influência de outros filósofos alemães, como Immanuel Kant (1724 - 1804) e Friedrich Hegel (1770 - 1831) (Ribeiro; Lobato \& Liberato, 2009). Mas, de acordo com Martin Sala (2018), a fenomenologia tem um ponto de partida bastante básico: antes de mais nada - ou, com maior precisão, vem de um ato psicológico. Nesta corrente, não existem diferenças entre percepção e sensação, sendo possível interpretar o mundo mediante a motivação, valores éticos e morais, interesses, julgamentos e expectativas daqueles que percebem (Chauí, 2000).

Desse modo, o enfoque fenomenológico privilegia o olhar para o objeto de estudo de uma posição pretensamente neutra e estritamente objetiva, o que se mostra mais próprio para as questóes humanas; não excluindo o valor de outras correntes teóricas, porém, acrescentando novas perspectivas e ampliando o universo do conhecimento (Leopoldino, Santos \& Caminha, 2020). Para Helbel \& Vestena (2017), a fenomenologia estabelece uma nova relação firmada na existência de interação entre o ser humano e o ambiente.

O geógrafo chinês Yi-Fu Tuan foi um importante fenomenologista, criador do neologismo "topofilia”, o qual inclui "[...] todos os laços afetivos dos seres humanos com o meio ambiente material. Estes diferem profundamente em intensidade, sutileza e modo de expressão" (Tuan, 1980, p. 107). O termo Topofilia (do grego topo, lugar e philos, amor; afeição), foi proposto para descrever os pressupostos individuais e coletivos de percepção, atitudes e ligação afetiva do ser humano para com o ambiente físico (Tuan, 1980). Tal conceito foi complementado pelas ideias do ecólogo americano Edward O. Wilson, em 1984, que propôs o termo Biofilia (do grego bios, vida e philos, amor; afeição), descrito como a tendência natural a voltarmos nossa atenção às coisas vivas e também como a ligação afetiva com outros organismos e habitats com o qual sentimos afinidade, numa necessidade intrínseca humana do contato com a natureza. Ainda de acordo com Tuan (1983, p. 4),

percepção é tanto a resposta dos sentidos aos estímulos externos, como a atividade proposital, na qual certos fenômenos são claramente registrados, enquanto outros retrocedem para a sombra ou são bloqueados. Muito do que percebemos tem valor para nós, para a sobrevivência biológica, e para propiciar algumas satisfaçôes que estão enraizadas na cultura.

Para Tuan, "a percepção é uma atividade, um estender-se para o mundo" (1980, p. 14), que ocorre de forma particular em cada indivíduo. O ser humano interpreta e apreende o seu meio físico e social por meio dos estímulos sensoriais que experimenta durante a sua vida. Nesse contexto, o papel dos sentidos é imprescindível ao processo de percepção ambiental e apreensão da paisagem vivida. Eles possibilitam o diálogo do ser humano com o mundo, ou seja, o mundo é percebido simultaneamente pelos cinco sentidos - visão, tato, audição, olfato e paladar -, que interagem na forma como o ser humano percebe e sente os fenômenos (Tuan, 1980). 
A perspectiva fenomenológica parte da compreensão do viver de cada sujeito. Ela não busca definiçôes ou conceitos a priori, mas desvenda os fenômenos além das aparências, considerando sua expressão na totalidade do mundo vivido (Leopoldino, Santos \& Caminha, 2020). A fenomenologia e a percepção ambiental colocam o ser humano e suas interpretaçóes sobre os lugares em evidência, simultaneamente lhes dando sentido, cabendo à compreensão das relações que estes estabelecem com os lugares (Helbel \& Vestena, 2017).

A fenomenologia se apresenta apropriada para fazer pesquisas no âmbito da educação, pois trabalha o real vivido, buscando a compreensão do que somos e do que fazemos, não carregando consigo a exigência de uma verdade teórica ou ideológica preestabelecida (Leopoldino, Santos \& Caminha, 2020). A base do conhecimento para a fenomenologia está na capacidade de o sujeito perceber o que está em seu mundo, implicando, assim, no processo de dar significado ao que foi percebido pelos sentidos e a realizar os vínculos entre o que foi apreendido.

Nesse sentido, a aprendizagem humana não se limita à intelectualidade, mas compreende a totalidade do ser. A percepção, a imaginação e as intuiçóes são consideradas no processo de aprendizagem. Aprendemos observando a nós mesmos e aos outros. Por isso, considerar a educação sob a ótica da fenomenologia significa conceber como fundamental a subjetividade que se configura pelas açôes pedagógicas (Leopoldino, Santos \& Caminha, 2020).

Os estudos de percepção ambiental partem da realidade de cada grupo social, pois cada sujeito constrói seus valores ao se relacionar consigo mesmo e com o meio que o cerca. Apesar de a literatura apresentar poucos estudos que associam a fenomenologia ao campo da percepção ambiental, defendemos, no presente estudo, que é possível e viável essa relação, tendo em vista que a perspectiva fenomenológica considera as formas individuais de sentir e perceber o espaço vivido. A investigação das percepções, conhecimentos e valores dos diferentes grupos sociais pode fornecer subsídios para a elaboração de programas e materiais educativos em prol da conservação ambiental.

\section{PERCEPÇÃO AMBIENTAL NA EDUCAÇÃO FORMAL E NÃO FORMAL}

Com o avanço da Ciência e da Tecnologia - C\&T, a questão ambiental se torna cada vez mais emergente. $\mathrm{O}$ ambiente é percebido de diversas formas diante do olhar de seus agentes transformadores, que por sua vez, constroem as suas percepçóes ambientais por meio de fatores culturais e socioespaciais. Nesse contexto, comparando a história da humanidade, temos a EA como algo novo e de grande relevância na tentativa de se acompanhar o desenvolvimento da dinâmica ambiental.

Pela dialética da transformação da relação entre ser humano e natureza, o trabalho é uma categoria fundamental para o entendimento da relação de que:

toda ação intencional sobre o ambiente é atividade humana. Essa mediação que completa o homem torna-o, ao mesmo tempo, ser natural e social. Por isso, o trabalho é uma categoria fundamental para o entendimento da relação homem-natureza (Saisse, 2011, p. 33).

O ser humano natural-histórico é capaz de criar o novo com sua consciência, e isso o diferencia dos demais animais que agem por uma necessidade imediata. Sobre o assunto em questão, torna-se válido lembrar as concepçóes de Vygotsky:

A consciência é entendida aqui como a percepção da atividade da mente, a consciência de estar consciente.

No entanto é uma fase extremamente importante no processo de formação de conceitos mais abstratos porque é nela que se dá o início da unificação das impressões desordenadas a partir das organizaçôes dos objetos discretos, vivenciados em grupo. Em suma, cria bases para organizaçóes posteriores, a partir da interiorização dos instrumentos culturais e da regulação do próprio comportamento (1999, p. 114).

A presença da EA ganhou notoriedade e reconhecimento quanto a sua importância estratégica para: a socialização de informações e conhecimentos, a autonomia dos grupos sociais, a participação popular e a democratização das decisões. O destaque se deu "pela concepção dialética de educação, que entende como 
atividade social de aprimoramento do sujeito pela aprendizagem e pelo agir, e que se alia aos processos de transformação societária” (Saisse, 2011, p. 166).

Dessa forma, percebe-se que um dos papéis da EA é o de trazer para a comunidade, discussões, reflexốes e socialização de experiências, como construto fundamental na abordagem da temática sobre percepção ambiental. Tais ações permitem aos sujeitos dialogarem sobre as suas opinióes acerca de diversos olhares sobre o meio em que vivem e também sobre suas ações neste meio.

O conceito de ambiente para a educação no processo de percepção ambiental expressa, portanto, um espaço percebido e materialmente produzido, com diferentes escalas de compreensão e intervenção, em que se operam as relações sociedade e meio natural. $\mathrm{O}$ ambiente é, também, resultado de interações complexas, limitadas em recortes espaço-temporais que permitem a construção do sentido de localidade, territorialidade, identidade e de pertencimento para os sujeitos (Loureiro, Azaziel \& Franca, 2003). Observamos esta visão sobre ambiente de acordo com Cunha e Leite (2009, p. 70):

A EA necessita de diagnósticos participativos, prognósticos e busca de ações apontadas pela comunidade como prioritários em suas vidas. Desta forma, apropriou-se dos conceitos, princípios e atividades da percepção ambiental, principalmente, para o entendimento do que pensam e de como vivem as pessoas, culturas, necessidades e lugares.

Nesse sentido, a educação atua no processo de ensino-aprendizagem, na problematização e reflexão de uma determinada realidade, com o conhecimento e a intervenção prática na construção de valores, condutas e meios instrumentais (técnicas) que propiciam determinado tipo de transformação da natureza para atender às nossas necessidades. Dessa forma, pensamos em uma EA comprometida com a ação transformadora centrada nas causas estruturais e nos processos, com implicaçôes socioambientais, que contribuem para uma visão coletiva dos sujeitos com a sua relação para com os recursos ambientais.

Por esta razão, a concepção da educação no processo de percepção ambiental distingue-se de outras concepçóes, cuja prática pedagógica parte da vertente da EA convencional, a qual permite o funcionamento dos sistemas ecológicos e a mudança da conduta individual como base do processo de ensino-aprendizagem em seu propósito central (Loureiro, Azaziel \& Franca, 2003).

Layrargues (2002) complementa a fala de Loureiro (2003) quando afirma que "a educação ambiental convencional preconiza o enfrentamento apenas da agressão humana à natureza” (p. 5), o que sinaliza uma visão reducionista sobre o estudo do ambiente. Enquanto que, Loureiro (2004a) contribui para esclarecer as diferenças entre a chamada EA convencional e a EA “transformadora”, na qual se inserem abordagens similares: emancipatória, crítica, popular, ecopedagógica, entre outras. Assim, observamos esta mesma perspectiva na fala de Layrargues (2002, p. 5):

Todas as novas adjetivaçôes - alternativa, crítica, emancipatória, popular, no processo de gestão ambiental, aparentemente, apresentam mais pontos em comum do que divergências. Elas dialogam entre si e colocam-se em oposição ao modelo clássico de educação ambiental que historicamente vem sendo consolidado, que apresenta fortes semelhanças a uma educação ambiental preservacionista ou conservacionista.

Então, qual é a importância da percepção ambiental para a educação? Mais do que nunca, recorrendo aos espaços de ensino formal e não formal, com o alcance dos meios de comunicação, a ciência amplia e provoca mutaçốes sociais e, ao mesmo tempo, recebe da sociedade influências que a (re)orientam em busca de respostas sobre situaçóes e problemas que acontecem no meio de convivência social.

A fim de promover uma EA transformadora, sob a visão de Cascais e Teran (2014), o planejamento escolar tomou novas formas com a valorização das experiências e atividades não escolares e, com isso, a visão sobre educação e a concepção de ensino tomaram formas mais abrangentes em relação aos seus espaços formais, não formais e informais. Segundo os mesmos autores, "geralmente, a diferença entre formal, não formal e informal é estabelecida tomando por base o espaço escolar” (Cascais \& Teran, 2014, p. 2). 
O ambiente escolar é campo fecundo para as relaçóes sociais, e a forma como o percebemos se diferencia da forma como o concebemos. A percepção de cada indivíduo sobre o ambiente é um processo individual. A educação formal tem um espaço delimitado para que ocorram as ações intencionais de aprendizagem, ou seja, ela é institucionalizada (Cascais \& Teran, 2014). Filho e Vidal (2000) concordam com essa visão quando afirmam que:

A construção de espaços adequados para o ensino, bem como a definição de tempos de aprendizagem, estava relacionada não apenas à possibilidade de a escola vir a cumprir as funções sociais que lhe foram crescentemente delegadas, mas, também, à produção da singularidade da instituição escolar e da cultura que lhe é própria (p. 20).

Além desses aspectos, há outra vertente, que versa sobre o conceito da palavra “disciplina”. Ela afirma que, no ambiente educacional, espaços e tempos são meticulosamente dispostos em função de regular a ação dos sujeitos, fazendo parte da ordem social e escolar, relacionando-se entre si e enfatizando a sua relevância na estruturação do sistema escolar (Foucault, 1997).

Atualmente, o espaço escolar é concebido como um ambiente no qual o ensino e a disciplina operam sobre os indivíduos que ali convivem. A organização deste ambiente em salas de aulas, a sua distribuição de estudantes em salas de aula mistas, o ordenamento do tempo escolar e a sua estruturação curricular em conteúdos disciplinares, retratam a busca constante para a construção de um modelo escolar de massas, que é ainda hoje um grande desafio.

Filho e Vidal (2000) criticam a organização do espaço formal de ensino, também evidenciada por Foucault (1997) e Cascais e Teran (2014). Ressaltam que há desafios ainda a serem compreendidos com a proposição de múltiplas trajetórias de institucionalização nestes espaços, a fim "de delimitá-los, controlá-los, materializando-os em quadros de anos/séries, horários, relógios, campainhas, ou em salas específicas, pátios, carteiras individuais ou duplas” (Filho \& Vidal, 2000, p. 21). Assim, percebe-se que há um conjunto de regras simbólicas nesses espaços, que caracterizam a sua concepção. Porém, cabe ressaltar aqui, que esta visão pode ser concebida de diversas formas, de acordo com a percepção individual ou coletiva daqueles que convivem e interagem em ambientes escolares.

Diante desse cenário, também temos a possibilidade de relacionar a aprendizagem aos conhecimentos adquiridos em diversos outros espaços, como: no ambiente familiar, nos passeios culturais, em ambientes religiosos, nos museus e centros de ciências, entre outros. Assim, todo contexto social nos remete à ação de aprendizagem, o que permite a percepção de ambientes não formais de ensino.

Dessa forma, os espaços não formais de ensino podem ser compreendidos como ambientes que nos remetem a espaços de educação, mas que são constituídos de forma diferenciada e de modo integrado ao sistema formal de ensino. Ou seja, são espaços em que a educação acontece fora do ambiente escolar. Nesses espaços,

“a educação não formal pode ser definida como a que proporciona a aprendizagem de conteúdos da escolarização formal em espaços como museus, centros de ciências, ou qualquer outro em que as atividades sejam desenvolvidas de forma bem direcionada, com um objetivo definido" (Vieira, Bianconi \& Dias, 2005, p. 21).

Assim, percebemos que tanto os espaços formais de ensino, quanto os espaços não formais de ensino são organizados e dispostos para determinadas finalidades onde há intenção e direcionamento nas ações e atividades a serem propostas e realizadas nesses ambientes.

\section{PERCEPÇÃO E EDUCAÇÃO AMBIENTAL}

A visão de uma natureza selvagem e preservada, distante do ser humano, promove concepções incorretas acerca do ambiente. Essa percepção foi denominada "mito moderno da natureza intocada”, por Diegues (2008), e tem relação com a falta de afeição e sentimento de pertencimento dos seres humanos com o ambiente 
em que vivem. A tendência de desligamento do ser humano da natureza é baseada nos princípios da ecologia radical ou profunda (deepecology), movimento originado nos Estados Unidos na década de 1980 (Diegues, 2008).

Os seres humanos estão inseridos completamente no ambiente, mesmo que este tenha se modificado com o tempo pelas açóes antrópicas, a ponto de pouco se perceber que anteriormente havia um ambiente natural. É fundamental que o ambiente seja visto de forma integrada e não apenas associado aos elementos naturais, como animais, florestas ou uma área de proteção ambiental. A ideologia preservacionista, na qual o ser humano é sempre responsável pela destruição ambiental e, portanto, deve ser mantido afastado da natureza, interfere na percepção que os indivíduos têm do meio em que fazem parte.

A percepção ambiental nem sempre é algo expresso ou verbalizado cotidianamente na vida das pessoas, mas isso não significa que ela não seja vivenciada. Os estudos de percepção ambiental buscam o conhecimento da relação que um determinado grupo social estabelece com o ambiente. Com isso, é possível promover a construção de pontes entre o pensamento naturalista e o pensamento globalizante (Torres, Moraes \& Delizoicov, 2008).

Na última década, vários trabalhos têm investigado as percepçôes de diferentes grupos sociais. Por exemplo, para a conservação e conhecimento de características e valores sobre os biomas brasileiros (Zillmer-Oliveira \& Manfrinato, 2011; Vieira, Vargas \& Zanon, 2015; Araújo \& Sovierzoski, 2016; Silva et al., 2017; Souza \& Silva, 2017; Castro, Carvalho \& Pessano, 2019; Zanini et al., 2020), para o conhecimento das relaçóes entre comunidades do entorno e Unidades de Conservação (Lucena \& Freire, 2011; Pradeiczuk, Renk \& Danieli, 2015; Pires et al., 2016; Custódio \& Leite, 2017; Gregório et al., 2018; Ferreira \& Profice, 2019) e para EA em várias regiốes do Brasil (Oliveira \& Corona, 2011; Silva et al., 2012; Marcomin \& Sato, 2016; Fischer et al., 2017).

É importante ressaltar que as percepções têm influência no processo de conservação das áreas naturais, tendo em vista que a maneira como as pessoas percebem estas áreas reflete nas suas atitudes em relação ao ambiente. Sendo assim, os estudos de percepção podem ser uma ferramenta eficaz para o planejamento de programas educativos e açóes de EA, visto que partem da realidade do público alvo, permitindo o conhecimento dos grupos sociais envolvidos, seus sentimentos, valores e atitudes em relação ao ambiente. Para isso, as atividades programadas devem partir das necessidades previstas previamente, levando em conta o contexto sociocultural.

Loureiro (2003) afirma que a EA tem sido produzida a partir de duas perspectivas: a conservadora e a transformadora. A EA conservadora busca, a partir de ações pontuais, a promoção de mudanças superficiais, o que mantém o status quo da sociedade. O atual modelo conservador de EA propõe alteraçóes de certas atitudes e comportamentos pessoais, sem que tais mudanças signifiquem mudanças no contexto ambiental contemporâneo em que se vive. Exemplificando, há cerca de um ano, ocorreram inúmeros focos de incêndio na região Amazônica brasileira, em que a floresta foi retirada para dar lugar à exploração de minérios e a implantação de novas áreas para pasto de gados destinados ao consumo. $\mathrm{Na}$ época, a EA voltou-se para falar dos serviços ambientais proporcionados pela floresta e a importância de sua conservação. Entretanto, não foi evidenciado como nossos hábitos alimentares e de consumo também estão relacionados com os impactos ambientais gerados, sendo divulgado à população apenas o episódio das queimadas e não a real raiz do problema. Tal procedimento, feito de maneira intencional ou não, leva a EA a acabar colaborando com a manutenção do modelo hegemônico de educação, o qual não promove a reflexão sobre o modo de vida e de consumo da sociedade (Rabello \& Oliveira, 2020).

Contudo, mesmo diante das limitaçôes que são inerentes à EA, existe a perspectiva que busca a atuação transformadora na sociedade, na qual os ideais de civilidade, sustentabilidade e ética são pautados como essenciais (Loureiro, 2004b). A EA transformadora parte do princípio que é necessário compreender e teorizar a atividade humana, buscando, a partir da sensibilização, o processo de construção de um mundo crítico, fundamentado e com aporte teórico para promover a construção de hábitos saudáveis e éticos.

A EA não tem como finalidade promover e valorizar apenas conhecimentos com valores universais, que no geral são ligados aos valores dos grupos dominantes. Ao contrário, ela busca estabelecer processos 
práticos e reflexivos que levem à consolidação de valores que possam ser entendidos e aceitos como favoráveis à sustentabilidade global, à justiça social e à preservação da vida (Loureiro, 2004b). Tal referência é de extrema relevância, visto que muito do que se observa em relação a projetos de EA conservadora são orientaçóes com objetivo de difundir os padróes culturais e comportamentais de certo grupo. Por outro lado, a EA transformadora promove o debate participativo e a reflexão ligada às particularidades ambientais e sociais que são únicas e exclusivas de cada localidade.

A partir da imposição do modo de vida de grupos poderosos, começam a ser instaurados conflitos na gestão democrática ambiental. Ou seja, em uma perspectiva de EA transformadora, existe a democratização do acesso à informação, entendendo que as realidades são diversas e que é importante dar espaço para a participação de todos os grupos. Desse modo, busca-se a incorporação da práxis ambiental como forma de luta dos diversos setores sociais e não apenas dos ambientalistas (Loureiro, 2005). Assim, é necessário ressignificar a EA, transformando-a em uma política educacional pública democrática consolidada. É importante também contextualizar que a qualidade de vida da sociedade é resultado do ambiente construído a partir dos processos produtivos e de consumo dominantes.

De acordo com Loureiro (2005), o conceito de ambiente adequado a ser adotado na EA é o de um espaço territorialmente percebido com diferentes escalas de compreensão e intervenção, no qual se operam as diversas relaçôes sociedade-natureza. Portanto, a EA é uma temática interdisciplinar, visto que é o resultado da interação entre sociedade e natureza, ambas fluidas e não estáveis.

Quando os programas ambientais são pautados apenas em atitudes comportamentais isoladas, desconsiderando o contexto local, podem promover o aumento da desigualdade social e da injustiça ambiental. Por isso, é fundamental o reconhecimento das diferentes percepçóes e contextos sociais. Não existe a construção de uma democracia ou educação para a cidadania sem a clara exposição dos conflitos e o conhecimento da realidade local. É necessário reconhecer que a sociedade é plural e nela existem percepções, valores, interesses e conhecimentos de mundo muito distintos.

\section{CONSIDERAÇÕES}

Os estudos de percepção ambiental partem da realidade de cada grupo social, permitindo o conhecimento dos sentimentos, valores, conhecimentos e relações que os indivíduos estabelecem com o ambiente em que vivem. Neste estudo, defendemos a ideia de que a fenomenologia relaciona-se aos estudos de percepção ambiental, tendo em vista que é uma perspectiva que considera as formas individuais de sentir e perceber o espaço vivido. Além disso, acreditamos que o estudo das percepçóes dos diferentes grupos sociais pode fornecer subsídios para a elaboração de programas e materiais educativos em prol da conservação ambiental.

Portanto, consideramos que seja possível, com as contribuições da percepção ambiental para a educação formal e não formal, reinventar uma ordem social que seja mais justa, democrática e ambientalmente segura. Esta proposta não é a única solução devido à sua relação utópica com a realidade, já que não basta apenas criarem leis e mais leis em prol de um bem-estar ambiental, mas sim, partir da sensibilização do olhar dos sujeitos, permitindo uma possível relação de respeito mútuo entre o ser humano e o ambiente.

As reflexões discorridas ao longo deste ensaio foram construtivas para que possamos trabalhar com a realidade concreta, pois este é o estímulo, para que a partir de um pensamento crítico possamos construir alternativas viáveis para que a EA estimule e potencialize o poder das diversas populações em prol de oportunidades para as mudanças democráticas de base dos setores populares da sociedade. 


\section{AGRADECIMENTOS}

À Coordenação de Aperfeiçoamento de Pessoal de Nível Superior (CAPES), pela concessão de bolsa de mestrado e doutorado, e ao Conselho Nacional de Desenvolvimento Científico e Tecnológico (CNPq), pela concessão de bolsa de produtividade.

\section{REFERÊNCIAS}

Acosta, A. L., Xavier, F., Chaves, L. S. M., Sabino, E. C., Saraiva, A. M., \& Sallum, M. A. M. (2020). Interfaces à transmissão e spillover do coronavírus entre florestas e cidades. Estudos Avançados, 34(99), 191-207. https://doi. org/10.1590/s0103-4014.2020.3499.012.

Araújo, B. F. de, \& Sovierzoski, H. H. (2016). Percepção dos alunos do ensino médio sobre os biomas de mata atlântica e caatinga. Revista Práxis, 8(16), 81-94. https://doi.org/10.25119/praxis-8-16-764.

Cascais, M. das G. A., \& Teran, A. F. (2014). Educação formal, informal e não formal na educação em ciências. Revista Ciência em Tela, 7(2), 1-10. http://www.cienciaemtela.nutes.ufrj.br/artigos/0702enf.pdf.

Castro, L. R. B., Carvalho, A. V. de, \& Pessano, E. F. C. (2019). Percepções de alunos do ensino fundamental sobre o bioma pampa, no Oeste do Rio Grande do Sul, Brasil. Revista Exitus, 9(4), 290 - 318. https://doi.org/10.24065/22379460.2019v9n4id1016.

Chauí, M. S. (1998). Convite à filosofia. 10ạ ed. São Paulo: Ática.

Chauí, M. S. (2000). Convite à filosofia. 12a ed. São Paulo: Ática.

Cunha, A. S., \& Leite, E. B. (2009). Percepção ambiental: implicações para a educação ambiental. Sinapse Ambiental, 6, 66-79. http://www4.pucminas.br/graduacao/cursos/arquivos/ARE_ARQ_REVIS_ELETR20090930145741.pdf.

Custódio, O. da S., \& Leite, N. K. (2017). Percepção ambiental dos moradores das comunidades de Ratones e Lagoa do Peri, Ilha de Santa Catarina. Extensio: R. Eletr. De Extensão, 14(25), 150-160. https://doi.org/10.5007/1807$0221.2017 \mathrm{v} 14 \mathrm{n} 25 \mathrm{p} 150$.

Diegues, A. C. (2008). O mito da natureza intocada. 6a ed. ampliada. São Paulo: Hucitec: Núcleo de Apoio à Pesquisa sobre Populaçôes Humanas e Áreas Úmidas Brasileiras/Nupaub-USP/CEC.

Faitanin, P. (2008). O papel dos sentidos internos na teoria do conhecimento de Tomás de Aquino. Aquinate, 6, 234-241. http://www.aquinate.com.br/textos/o-papel-dos-sentidos-internos-na-teoria-do-conhecimento-de-tomas-de-aquino/.

Ferreira, D. M., \& Profice, C. C. (2019). Percepção ambiental de unidades de conservação: o olhar da comunidade rural do barrocão no entorno do parque estadual da serra do Conduru - BA. Fronteiras: Journal Of Social, Technological and Environmental Science, 8(3), 179-195. http://dx.doi.org/10.21664/2238-8869.2019v8i3.p179-195.

Filho, L. M. de F., \& Vidal, D. G. (2000). Os tempos e os espaços escolares no processo de institucionalização da escola primária no Brasil. Revista Brasileira de Educação, 14, 19-34. www.scielo.br/pdf/rbedu/n14/n14a03.pdf.

Fischer, M. L., Parolin, L. C.,Vieira, T. B., \& Garbado, F. R. A. (2017). Bioética ambiental e educação ambiental: levantando a reflexão a partir da percepção. Revista Brasileira de Educação Ambiental, 12(1), 58-84. https://doi. org/10.34024/revbea.2017.v12.2271.

Foucault, M. (1997). Vigiar e Punir. Petrópolis: Vozes.

Gregório, A. de, Moser, A. de S., Costa, E. P. da S., \& Moreira, A. L. O. R. (2018). Parque do Cinquentenário: um estudo investigativo da percepção ambiental da comunidade integrada. Revista Valore, 3, 343-352. https://doi. org/10.22408/reva302018176343-352.

Helbel, M. R. M., \& Vestena, C. L. B. (2017). Fenomenologia e percepção ambiental como objeto de construção à Educação Ambiental. Revista Brasileira de Educaşão Ambiental (RevBEA), 12(2), 67-78. https://doi.org/10.34024/ revbea.2017.v12.2225. 
Krzysczak, F. R. (2016). As diferentes concepções de meio ambiente e suas visões. REI. Revista de Educação do IDEAU, 11(23), 1-18. https://www.bage.ideau.com.br/wp-content/files_mf/9c9c1925f63120720408c5260bb0080d355_1.pdf.

Kuhnen, A. (2009). Meio ambiente e vulnerabilidade a percepção ambiental de risco e o comportamento humano. Geografia (Londrina), 18(2), 37-52. http://dx.doi.org/10.5433/2447-1747.2009v18n2p37.

Layrargues, P. P. (2002). A conjuntura da institucionalização da Política Nacional de Educação Ambiental. OLAM: Ciência E̋ Tecnologia, 2(1), 1-14. https://www.periodicos.rc.biblioteca.unesp.br/index.php/olam/article/view/11788.

Leff, E. (2011). Saber Ambiental: Sustentabilidade, Racionalidade, Complexidade, Poder. Petrópolis: Vozes.

Leontiev, A. (1978). O desenvolvimento do psiquismo. Lisboa: Livros Horizonte.

Leopoldino, E. R., Santos, L. A. M., \& Caminha, I. O. (2020). Educação e Fenomenologia: a percepção de adolescentes acerca do bullying na escola. Revista Tempos e Espaços em Educação, 13(32), 1-22. https://doi.org/10.20952/revtee. v13i32.14087.

Loureiro, C. F. B. (2003). Premissas teóricas para uma educação ambiental transformadora. Ambiente $\mho^{\circ}$ Amp; Educação, 8(1), 37-54. https://periodicos.furg.br/ambeduc/article/view/897.

Loureiro, C. F. B., Azaziel, M., \& Franca, N. (2003). Educą̧ão ambiental e gestão participativa em Unidades de Conservação. Rio de Janeiro: Ibase.

Loureiro, C. F. B. (2004a). Educação ambiental transformadora. In: Layrargues, P. P. (Coord.). Identidades da educação ambiental brasileira. Brasília: Ministério do Meio Ambiente, 2004. 156 p.

Loureiro, C. F. B. (2004b). Educação ambiental e gestão participativa na explicitação e resolução de conflitos. Gestão em Ação, 7(1), 37-50. www.scielo.br/pdf/asoc/v11n2/v11n2a03.pdf.

Loureiro, C. F. B. (2005). Complexidade e dialética: contribuições à práxis política e emancipatória em educação ambiental. Educação छ̊ Sociedade, 26(93), 1473-1494. https://doi.org/10.1590/S0101-73302005000400020.

Lucena, M. M. A. de, \& Freire, E. M. X. (2011). Percepção ambiental sobre uma Reserva Particular do Patrimônio Natural (RPPN), pela comunidade rural do entorno, semiárido brasileiro. Educação Ambiental em Ação, 9(35). www. revistaea.org/artigo.php?idartigo $=991$.

Marcomin, F. E, \& Sato, M. (2016). Percepção, paisagem e educação ambiental: uma investigação na região litorânea de Laguna-SC, Brasil. Educą̧ão em Revista, 32(2), 159-186. https://doi.org/10.1590/0102-4698125694.

Marin, A. A. (2008). Pesquisa em educação e percepção ambiental. Pesquisa em Educação Ambiental, 3(1), 203-222. https://doi.org/10.11606/issn.2177-580X.v3i1p203-222.

Martin Sala, J. J. S. (2018). Psicologia e fenomenologia. Revista do NUFEN, 10(3), 1-21. https://dx.doi.org/10.26823/ RevistadoNUFEN.vol10.n03artigo33.

Oliveira, A. O., \& Mourão-Júnior, C. A. (2013). Estudo teórico sobre percepção na filosofia e nas neurociências. Neuropsicologia Latino Americana, 5(2), 41-53. https://dx.doi.org/10.5579/rnl.2012.0083.

Oliveira, K. de, \& Corona, H. P. (2011). A percepção ambiental como ferramenta de propostas educativas e de políticas ambientais. Revista Cientifica ANAP Brasil, 1(1). http://dx.doi.org/10.17271/198432401120084.

Oliveira, N. A. da S. (2006). A educação ambiental e a percepção fenomenológica, através de mapas mentais. REMEA - Revista Eletrônica do Mestrado em Educação Ambiental, 16, 32-46. https://doi.org/10.14295/remea.v16i0.2779 .

Pires, K. R. P., Marimon, B. S., Souza, T. R. S., Anacleto, T. C. da S., \& Laforga, G. (2016). Percepção ambiental e caracterização socioeconômica da comunidade do entorno do parque municipal do Bacaba, Nova Xavantina (MT). Caminhos de Geografia, 17(60), 1-15. https://doi.org/10.14393/RCG176001.

Portugal, C. A. (2002). Discussão sobre empirismo e racionalismo no problema da origem do conhecimento. Diálogos E̊ Ciência: Revista Eletrônica da Faculdade de Tecnologia e Ciências de Feira de Santana, 1(1), 1-19. 
Pradeiczuk, A., Renk, A., \& Danieli, M. A. (2015). Percepção ambiental no entorno da unidade de conservação Parque Estadual das Araucárias. Revista Grifos, 24(38/39), 13-32. https://doi.org/10.22295/grifos.v24i38/39.3272.

Rabello, A. M., \& Oliveira, D. B. de. (2020). Impactos ambientais antrópicos e o surgimento de pandemias. UNIFESSPA contra a Covid-19. https://acoescovid19.unifesspa.edu.br/images/conteudo/Impactos_ambientais_ antr\%C3\%B3picos_e_o_surgimento_de_pandemias_Ananza_e_Danielly.pdf.

Saisse, M. V. (2011). Sentidos e práticas da educação ambiental no Brasil: as unidades de conservação como campo de disputa. 2011. 217 f. Tese de doutorado (Programa de PósGraduação em Psicossociologia de Comunidades e Ecologia Social) - Universidade Federal do Rio de Janeiro.

Silva, A. D. V. da, Mendonça, A. W., Marcomin, F. E., Mazzuco, K. T. M., \& Becker, R. R. (2012). Percepção ambiental como ferramenta para processos de educação ambiental na universidade. REMEA - Revista Eletrônica do Mestrado em Educação Ambiental, 27. https://doi.org/10.14295/remea.v27i0.3188

Silva, M. L. A. da, Paiva, L. de S., Araújo, M. de F. V., \& Conceição, G. M. da. (2017). Percepção ambiental dos moradores do Parque Nacional da Chapada das Mesas, no domínio fitogeográfico do Cerrado Brasileiro. Revista Espacios, 38(22), p. 33-50. https://www.revistaespacios.com/a17v38n22/17382233.html

Souza, L. S. de, \& Silva, E. da. (2017). Percepção ambiental do bioma caatinga no contexto escolar. Revista Iberoamericana de Educação, 73(1), 67-86. https://rieoei.org/historico/documentos/7694.pdf

Torres,J. R., Mores, E. C. de, \& Delizoicov, D. (2008). Articulações entre a investigação temática e a abordagem relacional: uma concepção crítica das relaçóes sociedade-natureza no currículo de ciências. Alexandria: Revista de Educação em Ciência e Tecnologia, 1(3), 55-77. https://periodicos.ufsc.br/index.php/alexandria/article/view/37827/28911.

Tuan, Y. F. (1980). Topofilia: um estudo da percepção, atitudes e valores do meio ambiente. São Paulo: Difel.

Tuan, Y. F. (1983). Passing Strange and Wonderful: Aesthetics, Nature, and Culture. Island Press: University of Michigan.

Vieira, M. R. M., Vargas, I. A. de, \& Zanon, A. M. (2015). Percepção ambiental e representações do pantanal: uma análise com alunos do 5o ano do ensino fundamental, Rio Verde de Mato Grosso (MS). In Anais do VIII Encontro Pesquisa em Educação Ambiental - EPEA, Rio de Janeiro, RJ. http://epea.tmp.br/epea2015_anais/pdfs/plenary/45.pdf.

Vieira, V., Bianconi, M. L., \& Dias, M. (2005). Espaços não-formais de ensino e o currículo de ciências. Ciência e Cultura, 57(4), 21-23. http://cienciaecultura.bvs.br/scielo.php?script=sci_arttext\&pid=S0009-67252005000400014\&lng=en\&tlng=pt.

Vygotsky, L. S. (1999). Pensamento e linguagem. 2a ed. São Paulo: Martins Fontes.

Xavier, A. S., \& Nunes, A. I. B. L. (2015). Psicologia do desenvolvimento. 4a ed. Fortaleza: EdUECE.

Zanini, A. M., Vendruscolo, G. S., Milesi, S. V., Zanin, E. M., \& Zakrzevski, S. B. B. (2020). Percepçôes de estudantes do Sul do Brasil sobre a biodiversidade da Mata Atlântica. Interciencia, 45(1), 15-22. https://www.interciencia.net/ wp-content/uploads/2020/02/15_6565_Com_Zakrzevski_v45n1.pdf.

Zillmer-Oliveira, T., \& Manfrinato, M. H. V. (2011). Percepção ambiental sobre "meio ambiente" e "educação ambiental” de seringueiros no sudoeste da Amazônia, Mato Grosso, Brasil. Biotemas, 24(3), 119-128. https://doi. org/10.5007/2175-7925.2011v24n3p119.

\section{Alanza Mara Zanini}

Doutoranda em Educação em Ciências e Saúde. Estudante e pesquisadora. Universidade Federal do Rio de Janeiro, Rio de Janeiro - RJ, Brasil. Grupo Pesquisa de Divulgação Científica no Ensino de Ciências.

E-mail:alanzabiologia@gmail.com

\section{Amanda Ribeiro dos Santos}

Mestre em Ciência, Tecnologia e Educação. Docente da educação básica na rede privada de ensino na cidade de Duque de Caxias e do Rio de Janeiro - RJ, Brasil.

E-mail:arsantos2028@gmail.com 


\section{Chreiva Magalhães Malick}

Mestra em Educação em Ciências e Saúde. Docente da educação básica na Prefeitura da cidade do Rio de Janeiro - RJ, Brasil.

E-mail: chreiva@hotmail.com

\section{José Anderson de Oliveira}

Especialista no Ensino de Física. Docente da educação básica na rede privada de ensino na cidade de Petrópolis - RJ, Brasil.

E-mail: joseprofisica@gmail.com

\section{Marcelo Borges Rocha}

Doutor em Ciências Biológicas. Docente e Pesquisador. Centro Federal de Educação Tecnológica Celso Suckow da Fonseca, Rio de Janeiro RJ, Brasil. Grupo de Pesquisa de Divulgação Científica no Ensino de Ciências.

E-mail: rochamarcel036@yahoo.com.br

\section{Contato:}

Alanza Mara Zanini

Universidade Federal do Rio de Janeiro Av. Carlos Chagas Filho, 373 - Centro de Ciências da Saúde, Bloco A, $1^{\circ}$ andar- Sala 32 Cidade Universitária. Rio de Janeiro - RJ | Brasil

CEP 21.941-902

Editor responsável: Rosana Louro Ferreira Silva

\section{ERRATA}

DOI | http://dx.doi.org/10.1590/1983-21172021230127er

Na página 2, no título do ABSTRACT, onde se lê SOCIAL TECHNOLOGY IN THE PROGRAMMING OF A CRITICAL-TRANSFORMATIVE CURRICULUM IN SCIENCE EDUCATION.

Leia-se:

ENVIRONMENTAL PERCEPTION AND ENVIRONMENTAL EDUCATION STUDIES: A PHENOMENOLOGICAL APPROACH. 